\title{
A Systems Approach to Research Inquiry in Accounting: A Research Note
}

\section{Carolina Koornhof}

Department of Accounting and Finance, University of Pretoria

\section{ABSTRACT}

Accounting research is strongly influenced by the research methodology and methods adopted in the natural sciences. As a result many researchers in Accounting have steered away from non-formal or interpretative methods. From a methodological perspective, Accounting research therefore has a narrow base (Tomkins and Groves, 1983). A solution to expanding the research base may be to search for non-formal, naturalistic research methods in disciplines related to Accounting, where they are more established. The purpose of the article is to introduce a research method, employed in Management Information Systems (Mitroff, Betz, Pondy and Sagasti, 1974) that may be of value to postgraduate students and Accounting researchers engaged in non-formal and naturalistic research. It is hoped that the exposure to this and other research models will contribute towards the broadening of the Accounting research base.

JEL M41

\section{INTRODUCTION}

Research in Accounting has been greatly influenced by the research methodology of the natural sciences. Quattrone (2000) confirms that researchers in Accounting, aiming to become "scientific", have adopted the epistemology of the natural sciences, even though they deal with human and not exclusively with non-human issues. One result is that Accounting research is still dominated by ontological and epistemological assumptions acceptable within the formal "scientific method". Although the realistic, positivistic research approaches have undoubtedly contributed to the growth of knowledge in Accounting, they represent but one type of knowledge. Morgan (1983) suggests that other research strategies will generate other types of knowledge that have an equally important role to play in the development of Accounting research. Tomkins and Groves (1983) encourage Accounting researchers to increasingly explore research approaches beyond the pure "scientific approach" towards more non-formal, naturalistic and interpretive research topics. ${ }^{\prime}$ 
At present there is still a limited number of Accounting research papers that use more interpretative research methods. This lack of examples of naturalistic research approaches may act as a hindrance to researchers. ${ }^{2}$ A solution may be to look for appropriate research approaches or methods in disciplines related to Accounting, where a naturalistic research methodology is more established. These research methods may then be introduced to postgraduate students and Accounting researchers as feasible research models.

The purpose of this article is to introduce a research method in Management Information Systems that may be of value to Accounting researchers, especially those engaged in non-formal, naturalistic or qualitative research, where there may be a paucity of appropriate research methods. In 1974 Mitroff, Betz, Pondy and Sagasti developed a model that sought to highlight the processes involved in research inquiry. They used systems theory as a basis to explain the intricate network of relationships in the research process. The model assists the researcher by documenting the various steps in research inquiry and allowing the researcher to identify and follow those steps that are appropriate to his/her research. Although the flexibility of the model's design makes it appropriate to a wide spectrum of research, it is particularly useful in less formal, experimental and naturalistic research.

The article commences with a discussion of the elements and activities of the Mitroff-model. Then the use of the model in Accounting research and its advantages are identified. The article concludes with some remarks on the future of Accounting research and the potential use of the model in Accounting.

\section{THE MITROFF-MODEL}

In developing their model Mitroff, Betz, Pondy and Sagasti (1974) aimed to create a programme by which science could be studied from a holistic or systems perspective. They argued that there were aspects of science that could only be studied from a whole systems perspective and that anything less than a holistic view of science would fail to identify some of the essential features of science (Mitroff, 1974). The model identifies the different phases of problem solving, and also highlights various research approaches, styles and attitudes towards science. The model for problem solving (Mitroff, Betz, Pandy \& Sagasti, 1974) represents a systems view of the different varieties of scientific behaviour, illustrated in Figure 1. 
Figure 1 A system view of problem solving

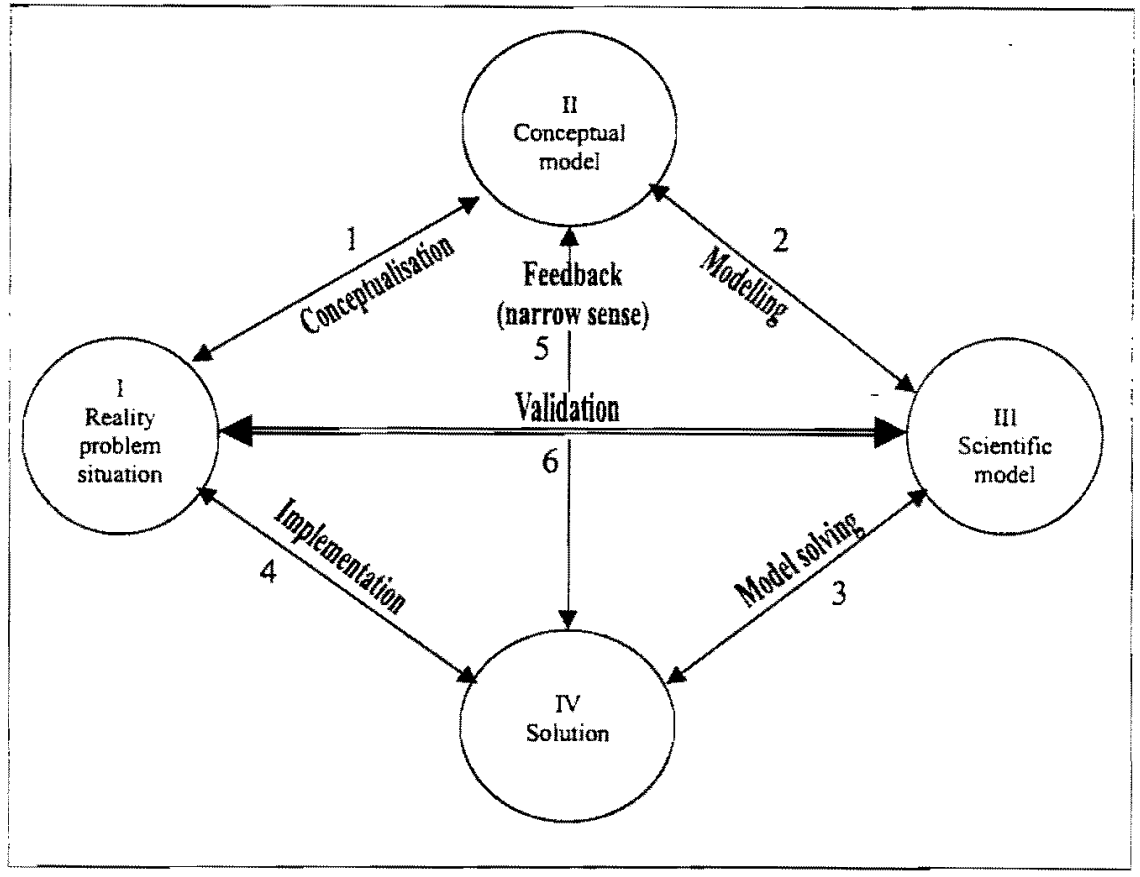

Source: Mitroff, I.I., Betz, F., Pondy, L.R., \& Sagasti, F. (May, 1974) "On Managing Science in the Systems Age: Two Schemes for the Study of Science as a Whole Systems Phenomenon", Interfaces, Vol 4, No 3: 46-58.

The systems view of the various kinds of scientific activity in the model results in a circularity, which implies that the diagram has no predefined beginning or end. Research does, however, have a beginning and thus a starting point. This starting point, together with the underlying assumptions of the researcher, has far-reaching consequences for the type of research that will be conducted and the subsequent stages of scientific inquiry that will be followed. The model implies that recognised and legitimate research does not have to start or end at a specific point, a view supported by Churchman and Ackoff (1950).

A research project could begin at either of circles I, II, III or IV. For example, the inquiry could commence at circle $I$, with the identification of an existing problem. The first phase of problem solving would then be the performance of activity 1 , conceptualisation, so as to devise a conceptual model in circle II. The conceptual model establishes, in broad terms, the definition of the particular problem to be solved. It specifies the field variables that will be used to define 
the nature of the problem and the level at which the variables will be treated (Mitroff et al., 1974: 47). For example, a financial problem may be viewed at different levels: From a country perspective (typically a macro perspective), or from an industry, company or individual perspective (increasingly a micro perspective).

The next phase may entail the performance of activity 2 , namely the formulation or development of a scientific model in circle III. A scientific model is a set of either qualitative or quantitative logical relationships, which link together the relevant features of the reality with which we, the researchers, are concerned (Rivett, 1972: 9). It should be borne in mind that the scientific model represents a simplified version of reality, consequently it is a form of reductionism (Hakanson, 1978).

The third phase concerns the performance of activity 3 to derive a solution (circle IV) from the scientific model. This function is related to the teleological dimension of Social Science, which assumes that the practice of science is invariable goal directed. Started in simple terms, the aim of social science is to provide a solution to a specified problem. This dimension may act as a constraint on research inquiry, because the problems that are addressed are often limited or restricted to the achievement of specified research goals (Mouton \& Marais, 1996: 15).

The implementation of activity 4 entails a feedback of the solution to the original problem or reality. This requires the implementation or utilisation of the solution to the problem area in society. It is apparent that the skills required for the implementation of a proposed solution differ from those required to develop a mathematical model. Mitroff et al. (1974: 50) confirm that the elements and activities in the model demand different skills and involve different standards or criteria of performance. For example, individuals who are convergers may excel in modelling while divergers may excel in implementation (Hudson, 1966).

In validation (activity 6) the degree of correspondence between reality and the scientific model may be evaluated. The comparison between the scientific model and reality may take place repeatedly until the scientific model is refined to reflect the necessary aspects of reality. Finally in activity 5 , that is, feedback in the narrow sense, problem solving activities (circles II, III, IV) are applied when the goal is to derive better scientific solutions. In this activity, continual feedback causes a solution to be refined so that it meets the criteria and field variables specified in the conceptual model. It is typical in this research cycle that no reference is made to reality and implementation does not occur. 
Given the simple system of interconnected elements in Figure 1, the authors calculated that a total of 3555 research subsystems could be formed by considering all possible combinations of two, three and four elements (Mitroff $e$ t al., 1974). The authors excluded activities that are related to only one element, because a system consists of at least two elements plus a relationship between them. Although not included in their total number of possible research subsystems, the authors did not preclude the possibility of subdividing activities 1 to 6 to incorporate, for example, different ways of performing the modelling or the conceptualisation activities. Such subdivision would substantially increase the number of research subsystems. Each of the research subsystems represents a different type or form of scientific activity. The model implies that legitimate research need not address all of the activities and elements in the model.

Mitroff et al. (1974) uses the example of a complex subsystem of scientific inquiry, illustrated in Figure 2 to demonstrate the application of the model.

\section{Figure 2 An application of the model of problem solving}

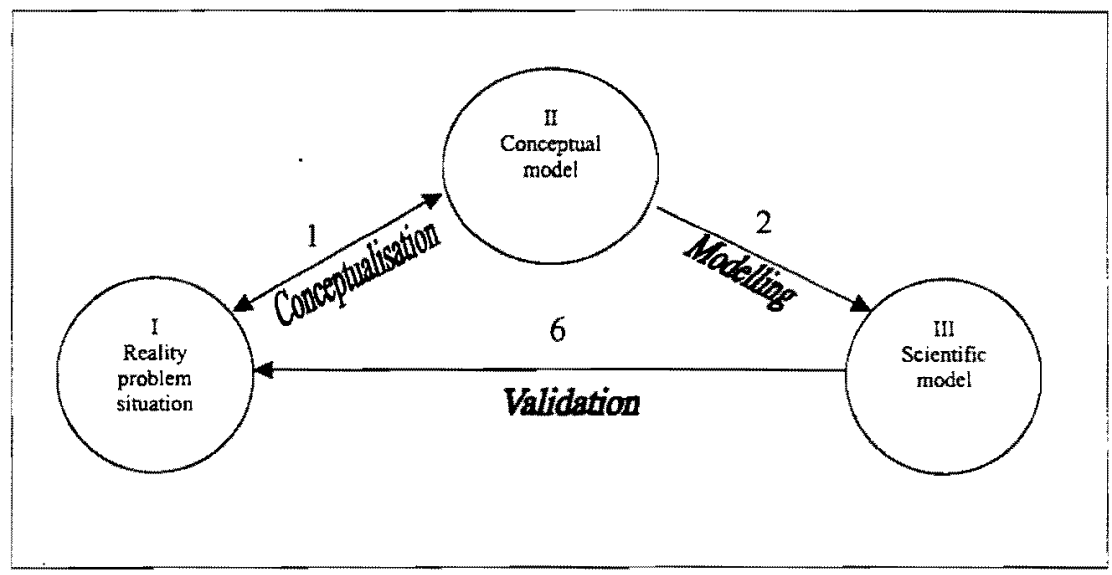

In this example, the starting point of research comprises both elements I and II. The activity of conceptualisation takes place by means of alternate consideration of reality and the problem situation on the one hand and the feasible conceptual models on the other. The outcome of activity 1 serves to influence the direction that will be taken in the modeling and validation activities that follow.

In judging performance in a research inquiry such as the one in Figure 2, different criteria should be used for each activity. The criteria appropriate to conceptualisation will be based on the ability to identify anomalies, formulate 
new or interesting problems and to identify puzzles or paradoxes. The criteria appropriate to the activity of modelling will be based on the ability to formulate "significant relationships within some formal system of abstract thought" (Mitroff et al., 1974). The activity of validation will be assessed on the research design and execution of the validity testing of the scientific model against the problem area or the reflection of reality.

\section{THE USE AND BENEFITS OF THE MODEL IN ACCOUNTING RESEARCH}

The Mitroff-model guides the researcher through the-research inquiry procedures that should be followed in solving a particular problem. The model may be appropriate to use in a wide spectrum of research beyond the realm of systems theory. It may be useful in both scientific and naturalistic research. The model was however, found to be especially useful in Accounting areas where well established research methods are lacking, for example where new knowledge is generated or naturalistic and exploratory research are undertaken.

The Mitroff-model was thus used in an Accounting thesis where the new concept of "flexibility" was introduced into the discipline. (Koornhof, 1998). The aim of introducing the new construct, was to develop a framework for the identification and measurement of information on flexibility in business organisations. It was posited that this information could then be communicated to users by means of the existing accounting information system (Koornhof, 1999). The exploratory and non-formal nature of the research presented the researcher with a problem, particularly as regards to the research approach, the structuring, legitimacy and validity of the research. To address these problems, the researcher selected the Mitroff-model proposed in Management Sciences and used the model to:

- define the scope of the research;

- provide guidance in structuring the research; and

- identify the thought processes and research stages that should be followed in conducting research in Accounting.

The phenomenon "flexibility" was observed in the behaviour of management in organisations, but no attempt had been made to recognise and measure the multi-dimensional phenomenon in Accounting. The research commenced at the activity "conceptualisation" (refer to Figure 1) with the purpose of refining "flexibility" into a workable construct. The construct was developed by defining the term, delineating the field of study, categorising flexibility, and by assessing the role of these categories in the organisation. Using the activity of 
"modelling", a framework consisting of six categories, four aspects and three levels of flexibility was developed. The construct was then introduced into Accounting with the view to identifying and measuring information on flexibility and communicating it to users of financial information. The activity of "model solving" resulted in the use the framework to develop indicators of flexibility. Suggestions on procedures that management and accountants could use to develop the flexibility indicators for their businesses, were also addressed.

The Mitroff-model was used in the research design and to divide the thesis into logical chapters. The scope of the research on flexibility in the thesis was confined to circles I, II, III and IV and activities 1,2,3 and 5 of the model. Activities 4 (implementation) and 6 (validation) were not included due to the exploratory nature of the research. The application of the Mitroff-model in Accounting research provided evidence that the model may be useful in disciplines other than Management Sciences, where it was originally developed.

The author found the model to be a valuable tool in Accounting research especially in areas where there is a lack of suitable research approaches and methods:

- Its circles and activities were helpful in delineating the scope of research;

- the circles also assisted the researcher to segment the research project into chapters;

the various research activities suggested an appropriate and logical sequence of chapters;

it prompted appropriate thought processes at various stages in the research project, for example, lateral thinking during conceptualisation and logical reasoning during modelling;

it encouraged a holistic approach to scientific endeavour;

it supported a process-related approach, because the model has no specific beginning or end and provides for continuous feedback;

it provided legitimacy to an exploratory and non-formal research topic; it dispelled misconceptions about research such as the following:

- research should cover all activities identified in the model;

- research must be validated;

- $\quad$ research must be implemented; and

it highlighted altemative research approaches and styles that can be adopted. 


\section{CONCLUDING REMARKS}

From a methodological perspective, Accounting research has developed from a narrow base. Tomkins and Groves (1983) suggest that in the past accounting researchers have generally ignored or been unaware of the existence of more naturalistic and non-formal research approaches, and the adherence to so-called scientific methods has resulted in a very narrow foundation for accounting research. The "scientific approach" has not only dominated research approaches and methods, but also influenced views and opinions as to what constitutes "legitimate" research. Researchers in Accounting have tended to concentrated on applied research where well established research methods existed, rather than venturing into high risk areas of pure and exploratory research where recognised research methods are often lacking. Hakanson (1978) contends that because of the formalised approaches by Accounting researchers, there has not been major advances in accounting knowledge during recent years. He suggests that the greatest contributions to knowledge in the Financial Sciences has come from Finance rather then Accounting. Perhaps the growth in Accounting research can be stimulated by encouraging pure research, by exploring opportunities requiring naturalistic and non-formal approaches and by developing new research frameworks.

The purpose of this article has been to encourage the development of such innovative research approaches. It hopes to introduce postgraduate students and researchers to a research framework from Management Accounting Systems that may be useful to Accounting research in more qualitative research areas, where appropriate research methods may not be found. There exists a need to broaden the foundation for accounting research. To realise this aim, Accounting researchers should become more "adventurous" in their research by exploring new or different approaches to conducting research.

\section{ENDNOTES}

1 The terms "scientific" versus "naturalistic" research approaches are defined by Abdel-Khalik and Ajinkya (1983). Formal research and Nonformal research are defined by Churchman (1961).

2 See Morgan and Willmot (1993) for a list of Accounting Journals publishing the "new" and "softer" types of Accounting research. 


\section{REFERENCES}

1 ABDEL-KHALIK, A.R. \& AJINKYA, B.B. (1983) "An Evaluation of 'The Everyday Accountant' and Researching His Reality", Accounting Organisations and Society, 8 (4): 375-84.

2 CHURCHMAN, C.W. (1961) Prediction and Optimal Decision: Philosophical Issues of a Science of Values, Prentice Hall, New Jersey.

3 CHURCHMAN, C.W. \& ACKOFF, R.L. (1950) Methods of Inquiry, Educational Publishers, Saint Louis.

4 HAKINSON, N.H. (1978) "Where We Are in Accounting: A Review of 'Statement on Accounting Theory and Theory Acceptance"' The Accounting Review, LIII (3): 717-25.

5 HUDSON, L. (1966) Contrary Imaginations, Schocken Books, New York.

6 KOORNHOF, C. (1998) "Accounting Information on Flexibility", Unpublished doctoral thesis, University of Pretoria, Pretoria.

7 KOORNHOF, C. (1999) "Information of Flexibility", Paper presented at the IAAER conference, Japan.

8 MITROFF, I.I. (1974) The Subjective Side of Science: A Philosophical Inquiry into the Psychology of the Apollo Moon Scientists, Elsevier.

9 MITROFF, I.I.; BETZ, F; PONDY, L.R. \& SAGASTI, F. (1974) "On Managing Science in the Systems Age: Two Schemes for the Study of Science as a Whole Systems Phenomenon", Interfaces, 4(3): 46-58.

10 MOUTON, J. \& MARAIS, H.C. (1996) Basic Concepts in the Methodology of the Social Sciences, Human Sciences Research Council, Pretoria.

11 MORGAN, G. \& WILLMOT, H. (1993) "The "New' Accounting Research: on Making Accounting more Visible", Accounting, Auditing and Accountability Journal, Vol. 6(4): 3-36.

12 MORGAN, G. (1983) Beyond Method: A Study of Organizational Research Strategies, Sage, Beverley Hills.

13 QUATTRONE, P. (2000) "Constructivism and Accounting Research: Towards a Trans-Disciplinary Perspective", Accounting, Auditing and Accountability Journal, 13 (2): 130-55.

14 RIVETT, Z.P. (1972) Principles of Model Building, John Wiley, London.

15 TOMKNNS, C. \& GROVES, R. (1983) "The Everyday Accountant and Researching His Reality", Accounting, Organisations and Society, 8.(4); 36174. 